\title{
PERCEPÇÃO DOS ANALISTAS FINANCEIROS SOBRE A RELEVÂNCIA DA INFORMAÇÃO CONTÁBIL NO SETOR ELÉTRICO
}

\author{
PERCEPTION OF FINANCIAL ANALYSTS ABOUT THE RELEVANCE OF \\ INFORMATION IN THE ELECTRIC SECTOR
}

\author{
AMANDA MEDEIROS MARTINS \\ Mestra em Ciências Contábeis pela Universidade Federal do Rio de \\ Janeiro (UFRJ). Endereço: FACC - PPGCC, Av. Pasteur, 250 / Urca / \\ 22290-240 / Rio de Janeiro/RJ / Brasil. \\ E-mail: amedeirosmartins@gmail.com
}

\section{ADOLFO HENRIQUE COUTINHO E SILVA}

Doutor em Contabilidade e Controladoria pela Universidade de São Paulo (USP). Professor Adjunto da FACC-UFRJ. Endereço: FACC PPGCC, Av. Pasteur, 250 / Urca / 22290-240 / Rio de Janeiro/RJ / Brasil.

E-mail: adolfocoutinho@uol.com.br

\section{RESUMO}

O objetivo desta pesquisa é analisar as percepções dos analistas de investimentos e analistas de crédito quanto à utilidade das informações contábeis societárias e regulatórias do setor elétrico. Para tanto, foram enviados questionários, no período de fevereiro a abril de 2017 , para 56 analistas financeiros indicados nos sites das concessionárias de energia elétrica. A taxa de resposta foi de $46 \%$, ou seja, a pesquisa obteve 26 respondentes, dos quais 14 são analistas de investimento e 12 analistas de crédito. Os resultados evidenciaram que: i) os itens da demonstração de resultado são mais relevantes que os itens do balanço patrimonial; ii) os analistas de investimento consideram a Demonstração do Resultado do Exercício regulatória mais adequada para suas análises do que os analistas de crédito e similares; iii) a percepção do prejuízo para a análise devido ao atraso na divulgação das demonstrações regulatórias foi maior para os analistas de investimento do que para os analistas de crédito e iv) o atual formato de divulgação (uma demonstração contábil societária e outra regulatória) das informações financeiras das empresas de energia elétrica não é considerado o ideal para os analistas financeiros.

Palavras-chave: Relevância da informação. Contabilidade regulatória. Contabilidade societária. Setor elétrico.

\begin{abstract}
The main objective of this research is to analyze the perceptions of investment analysts and credit analysts regarding the information of the corporate and regulatory accounting information of the electricity sector. Questionnaires were sent, in the period of February until April 2017, to 56 financial analysts indicated on the websites of the electric energy concessions. The response rate was $46 \%$, that is, a survey obtained 26 respondents of which 14 are investment analysts and 12 credit analysts. The results showed that: i) the items in the income statement are more relevant than the balance sheet items; ii) investment analysts consider a regulatory income statement more suitable for their analyzes and credit analysts and the like; iii) a perception of impairment for an analysis, due to the delay in disclosure of regulatory statements, was greater for investment
\end{abstract}


analysts than the credit analyst; and iv) the current format for disclosure of financial information of electricity companies is not considered ideal for financial analysts.

Keywords: Relevance of information. Regulatory accounting. Corporate accounting. Electrical sector.

\section{INTRODUÇÃO}

No Brasil, em novembro de 2009, o Comitê de Pronunciamentos Contábeis (CPC) elaborou a interpretação técnica ICPC 01 - Contratos de Concessão, que regulamentou a forma de contabilização para as concessionárias. Após aprovada à deliberação da Comissão de Valores Mobiliários - CVM no 611/2009, a ICPC 01 passou a ser obrigatória para empresas brasileiras de capital aberto a partir do ano de 2010.

Antes dessa interpretação, a infraestrutura do setor de energia era contabilizada como ativo imobilizado. Após a regulamentação da norma, os preparadores da informação passaram a verificar a infraestrutura pública do contrato de concessão como ativo financeiro e/ou ativo intangível.

Em dezembro de 2010, a fim de esclarecer dúvidas sobre a ICPC 01, foi emitida a orientação OCPC 05 - Contratos de Concessão. Para o setor elétrico, a OCPC 05 estabeleceu que o tratamento contábil que melhor reflete as operações das empresas de transmissão é o reconhecimento da infraestrutura como ativo financeiro, pois a atividade possui o direito incondicional de receber caixa ou qualquer outro ativo financeiro por parte do poder concedente. Por outro lado, as empresas de distribuição e de geração tendem a se adequar mais ao modelo bifurcado, ou seja, parte contabilizada como ativo financeiro e parte como ativo intangível (OCPC 05 - itens 63 a 130, 2010).

A Agência Nacional de Energia Elétrica (ANEEL) não aprovou a totalidade das alterações causadas pela adoção das normas supracitadas. A agência então instituiu a contabilidade regulatória por meio da Resolução Normativa ANEEL no 396/2010, que reformulou o Manual de Contabilidade do Setor Elétrico (MCSE), a fim de atender às necessidades da agência reguladora.

A ANEEL, por meio da Resolução Normativa no 605, de 11 de março de 2014, aprovou a atualização do Manual de Contabilidade do Setor Elétrico, com a intenção de contemplar um novo plano de contas para o setor. A partir de 2015, as concessionárias foram obrigadas a apresentar as demonstrações regulatórias mais completas, incluindo notas explicativas e o relatório da auditoria independente. Anteriormente, a ANEEL exigia apenas a divulgação das contas que foram impactadas devido a diferenças de práticas contábeis.

Em novembro de 2014, foi emitida a orientação OCPC 08 que tem como objetivo abordar os requisitos básicos do registro inicial e mensurar posteriormente os efeitos do reconhecimento de ativos e/ou passivos que tratam das tarifas regulatórias nas demonstrações societárias. Sua aplicação é exclusiva às empresas de distribuição de energia elétrica (CPC. OCPC no 08, 2014). Notadamente, a implantação da OCPC 08 possibilitou uma aproximação entre a norma societária e a regulatória, no que se refere ao setor de distribuição.

Assim, as empresas concessionárias de distribuição de energia elétrica aditaram seus contratos identificando o Poder Concedente como contraparte responsável pela liquidação dos ativos e passivos regulatórios, que, mesmo em caso de extinção, serão incluídos na base de indenização. Com isso, os órgãos responsáveis pelas normas contábeis entenderam que não existem mais incertezas que impossibilitem o reconhecimento e a mensuração dos ativos e passivos regulatórios das distribuidoras de energia elétrica (CPC. OCPC ํo 08, 2014).

$\mathrm{Na}$ concepção do órgão regulador do setor elétrico, a introdução da ICPC 01 nas empresas de energia elétrica do Brasil não causou melhoria na qualidade da informação (ANEEL, 2010).

No estudo de Ribeiro (2016), o analista da ANEEL entrevistado afirmou que a IFRIC 12 se adequa perfeitamente às concessionárias de rodovias e por isso seus exemplos são todos relacionados a esse segmento. Para o regulador do setor elétrico, a elaboração de estimativas para remuneração tarifária e o reconhecimento da infraestrutura no modelo bifurcado não reflete 
o valor fidedigno da atividade econômica, já que apenas o ativo financeiro é atualizado, o que dificulta a fiscalização realizada pelo órgão (Ribeiro, 2016). Ribeiro (2016) também afirma que há concordância sobre as dificuldades que as empresas enfrentam na adequação dos sistemas, a preocupação com a qualidade da informação e sobre a aproximação das demonstrações societárias e regulatórias com a adoção da OCPC 08. Por outro lado, foi possível identificar que ainda não há consenso sobre a possibilidade de unificação de tratamento contábil para o setor elétrico.

Por sua vez, Hoppe (2012) concluiu, na sua pesquisa, que é positiva a divulgação ao público das informações regulatórias, com a finalidade de complementar o volume de dados que já vem sendo divulgado por meio das demonstrações societárias.

Diante do exposto, o presente estudo possui o objetivo de analisar as percepções dos analistas de investimentos e analistas de crédito quanto à utilidade das informações contábeis societárias e regulatórias do setor elétrico.

Uma das motivações para realização desta pesquisa reside no fato de que, durante a sua realização, foram identificados poucos estudos nacionais que procurassem compreender a relevância da informação contábil do setor elétrico junto aos analistas financeiros.

Como contribuição prática, este estudo pretende investigar e relatar a percepção dos usuários da informação do setor elétrico quanto às informações contábeis divulgadas em dois modelos diferentes e assim auxiliar os órgãos reguladores (do setor e do mercado de capitais) na elaboração de regulamentos contábeis de mensuração, reconhecimento e divulgação, levando em consideração a necessidade dos usuários. Este trabalho também espera contribuir para a literatura da relevância da informação, no que se refere à compreensão da heterogeneidade dos usuários e suas necessidades distintas.

\section{ESTUDOS ANTERIORES}

A relevância da informação contábil vem sendo discutida há cerca de cinco décadas e ainda assim permanece um assunto atual, já que sua definição e aplicação são consideradas subjetivas e complexas. Morton (1974) se preocupou em compreender a relação entre os conceitos de relevância e compreensibilidade das demonstrações financeiras por preparadores, auditores e analistas de mercado.

Mais recentemente, pesquisadores analisaram as diversas fontes de informação e as demonstrações financeiras foram consideradas como principal fonte de informação para uma gama de usuários, na maioria dos estudos, os investidores e credores, investigados em diferentes mercados desenvolvidos.

Apesar de a demonstração financeira ser a principal fonte de informação para os usuários externos, Zimmerman (2013) afirma que nunca escutou algo como "vamos melhorar a qualidade dos relatórios financeiros externos para aumentar a riqueza do investidor" e também diz que os Chief Financial Officers (CFOs) veem as demonstrações financeiras como uma atividade de conformidade e não como uma forma de aumentar o valor da empresa.

Ainda assim, é a informação que faz parte da tomada de decisão dos usuários, mesmo que o aumento da sua qualidade não necessariamente seja o principal efeito para aumentar o valor da empresa. É importante que a informação seja fidedigna e relevante para os provedores de capital.

O Figura 1 apresenta estudos que abordam a utilidade/relevância da informação por parte dos usuários, particularmente os investidores e credores. São estudos que foram realizados por meio de instrumentos de pesquisa, como os questionários, as entrevistas ou o experimento.

Apesar da importância atribuída à demonstração como principal fonte de informação, o estudo de Bartlett e Chandler (1997) mostrou que mesmo com o passar dos tempos a percepção da utilidade dos relatórios contábeis por parte dos investidores ingleses não se modificou tanto. Entretanto, as pesquisas foram realizadas em épocas de pouca tempestividade e difícil acesso à informação. Adicionalmente, os resultados apresentam-se contraditórios, uma vez que consideram as demonstrações financeiras como fonte principal para tomada de decisão e pouco utilizadas. 
Ainda, de acordo com o Figura 1, pode-se observar que, tanto para mercados emergentes como para os desenvolvidos, a informação contábil é a principal fonte segundo os usuários contemplados pela literatura, e que as recentes pesquisas sobre as percepções da utilidade da informação contábil foram realizadas em mercados emergentes.

Com base nos estudos destacados, percebe-se que há pouca atribuição de valor por parte dos investidores e credores aos relatórios não financeiros, como o socioambiental e a declaração do presidente da companhia (mensagem da administração), enquanto que o relatório do auditor possui maior importância quando comparado com os supracitados. Apesar disso, Hodge (2003) afirma que os investidores consideram as informações financeiras auditadas mais relevantes, porém acreditam que houve uma perda na sua fidedignidade, devido à percepção da diminuição da independência entre as firmas de auditoria e as empresas.

Conforme demonstra a Figura 1, os estudos selecionados possuem uma abordagem qualitativa e a utilização de questionários como instrumento de coleta. É possível notar que com o decorrer dos anos a taxa de resposta foi diminuindo em relação às pesquisas mais antigas.

Por meio dos estudos examinados, os usuários (investidores e credores) consideram o balanço patrimonial, as demonstrações de resultado e os fluxos de caixa como itens mais importantes das demonstrações financeiras, conforme já previa a literatura. Em países menos desenvolvidos, os fluxos de caixa não se mostraram tão importantes, sugerindo que há uma baixa maturidade por parte dos usuários e também que as empresas possuem uma qualidade de divulgação insuficiente.

Constata-se que tanto os usuários dos mercados emergentes como os dos desenvolvidos possuem necessidades distintas para o uso da informação. Existem diferenças dentro dos subgrupos dos usuários e também compreensões divergentes. Enquanto uns possuem ferramentas mais sofisticadas e apenas captam os dados contábeis para alimentar suas bases e realizar suas avaliações, outros estão limitados ao que as empresas divulgam e complementam essas informações com dados não financeiros divulgados pela mídia. 


\begin{tabular}{|c|c|c|c|c|}
\hline Autor (ano) & Objetivo & $\begin{array}{c}\text { Método de } \\
\text { pesquisa/coleta de dados }\end{array}$ & Amostra/País & Resultado do Estudo \\
\hline Morton (1974) & $\begin{array}{l}\text { Demonstrar a relação, se houver, } \\
\text { entre os conceitos de relevância } \\
\text { e compreensão, percebidos por } \\
\text { quatro grupos de participantes no } \\
\text { processo de elaboração de } \\
\text { relatórios financeiros, em relação } \\
\text { à divulgação de dados } \\
\text { financeiros. }\end{array}$ & $\begin{array}{l}\text { Questionários. Auditores, } \\
\text { controllers, analistas de } \\
\text { crédito e de seguros. }\end{array}$ & $\begin{array}{l}\text { Do universo de } 213 \text {, a } \\
\text { taxa de resposta foi de } \\
63 \% \text {. } \\
\text { Estados Unidos. }\end{array}$ & $\begin{array}{l}\text { Há uma tendência positiva na relação dos objetivos da } \\
\text { compreensibilidade x relevância. O estudo sugere que as } \\
\text { informações mais compreensíveis são consideradas mais } \\
\text { relevantes. Insinua que as informações desfavoráveis podem ser } \\
\text { inerentemente mais difíceis de entender. Pode a empresa } \\
\text { apresentar intencionalmente divulgações desfavoráveis de forma } \\
\text { mais incompreensiva. }\end{array}$ \\
\hline $\begin{array}{l}\text { Bouwman, } \\
\text { Frishkoff e } \\
\text { Frishkoff } \\
(1995)\end{array}$ & $\begin{array}{l}\text { O objetivo deste estudo é } \\
\text { observar os analistas financeiros } \\
\text { enquanto eles formulam uma } \\
\text { decisão de investimento. }\end{array}$ & $\begin{array}{l}\text { Questionários e entrevistas. } \\
\text { Analistas financeiros. }\end{array}$ & $\begin{array}{l}\text { Dos } 20 \text { entrevistados, a } \\
\text { amostra final } \\
\text { representou } 40 \% \text { da } \\
\text { população identificada. } \\
\text { Estados Unidos (São } \\
\text { Francisco e Nova } \\
\text { lorque) }\end{array}$ & $\begin{array}{l}\text { Os resultados sugerem que a informação baseada em GAAP serve } \\
\text { principalmente para uma função de triagem, eliminando rapidamente } \\
\text { os usuários "pouco atraentes". No entanto, desempenha um papel } \\
\text { muito menos importante no desenvolvimento de um caso positivo } \\
\text { para investir na empresa. Essa decisão depende em grande parte } \\
\text { das informações qualitativas e da informação sobre os segmentos } \\
\text { individuais. Ao decidir em que empresa investir, os analistas buscam } \\
\text { informações desagregadas e futuras que lhes permitam avaliar o } \\
\text { potencial de ganhos de segmentos individuais. }\end{array}$ \\
\hline $\begin{array}{l}\text { Bartlett e } \\
\text { Chandler } \\
\text { (1997) }\end{array}$ & $\begin{array}{l}\text { Objetivo de examinar se os } \\
\text { acionistas utilizam e } \\
\text { compreendem as informações } \\
\text { dos relatórios das empresas. } \\
\text { (Uma réplica dos estudos de Lee } \\
\text { e Tweedie na década de } 70 \text { ) }\end{array}$ & $\begin{array}{l}\text { Questionários adaptados } \\
\text { de Lee e Tweedie. Período } \\
\text { de aplicação: dezembro de } \\
\text { 1994. Foi identificado um } \\
\text { grupo de acionistas de uma } \\
\text { empresa para serem } \\
\text { enviados os questionários. }\end{array}$ & $\begin{array}{l}\text { Do universo de } 300 \text {, a } \\
\text { taxa de resposta foi de } \\
25,3 \% \text {. } \\
\text { Reino Unido }\end{array}$ & $\begin{array}{l}\text { Os resultados encontrados demonstram que os relatórios contábeis } \\
\text { anuais continuam não sendo amplamente lidos. O nível de } \\
\text { informação voluntária aumentou. No entanto, pode ser uma } \\
\text { estratégia da administração para tentar manipular os acionistas. } \\
\text { Poucos leem as novas seções, ou porque precisam se familiarizar } \\
\text { com as novas normas ou porque não consideram importante. Por } \\
\text { fim, é pouco provável que as demonstrações anuais de uso geral } \\
\text { satisfaçam as necessidades de informação de um grande escopo de } \\
\text { investidores. }\end{array}$ \\
\hline $\begin{array}{l}\text { Ho e Wong } \\
(2001)\end{array}$ & $\begin{array}{l}\text { O objetivo é explorar a prática, as } \\
\text { percepções da eficácia (e } \\
\text { maneiras de melhorar) da } \\
\text { divulgação corporativa pelas } \\
\text { empresas cotadas em Hong } \\
\text { Kong. Compara percepções } \\
\text { sobre a variedade do fluxo de } \\
\text { informação, divulgação e das } \\
\text { questões do mercado eficiente. }\end{array}$ & $\begin{array}{l}\text { Questionários. Aplicados de } \\
\text { novembro de } 1997 \text { a janeiro } \\
\text { de 1998. Preparadores da } \\
\text { informação e analistas de } \\
\text { investimento. }\end{array}$ & $\begin{array}{l}\text { Foram } \quad 610 \\
\text { preparadores e } 535 \\
\text { usuários entrevistados. } \\
\text { Com uma taxa de } \\
\text { resposta de } 16,8 \% \text { e } \\
17,2 \% \text {, } \\
\text { respectivamente. } \\
\text { China. }\end{array}$ & $\begin{array}{l}\text { Analistas identificaram, mais que os preparadores, que há } \\
\text { necessidade de aumento da fiscalização dos relatórios financeiros. } \\
\text { Ambos os grupos não acreditam que a melhoria da divulgação seja } \\
\text { o único requisito suficiente para acabar com os problemas da } \\
\text { informação financeira. Em vez disso, eles sugeriram a necessidade } \\
\text { de melhoria na comunicação e, por meios mais adequados, uma } \\
\text { estratégia de divulgação mais proativa e mais informações } \\
\text { voluntárias requeridas pelos usuários. }\end{array}$ \\
\hline
\end{tabular}

Continua 
Figura 1 (continuação)

\begin{tabular}{|c|c|c|c|c|}
\hline Autor (ano) & Objetivo & $\begin{array}{c}\text { Método de } \\
\text { pesquisa/coleta de dados }\end{array}$ & Amostra/País & Resultado do Estudo \\
\hline Hodge (2003) & $\begin{array}{l}\text { O artigo investiga se os } \\
\text { investidores não profissionais } \\
\text { percebem as preocupações da } \\
\text { SEC quanto ao trabalho do } \\
\text { auditor independente e sobre a } \\
\text { confiança da informação } \\
\text { financeira auditada e da análise } \\
\text { fundamentalista. }\end{array}$ & $\begin{array}{l}\text { Questionários. Dividido em } \\
\text { dois grupos, um pré- } \\
\text { anúncio de premiação para } \\
\text { os respondentes e outros } \\
\text { pós-anúncios. Investidores } \\
\text { da NAIC. }\end{array}$ & $\begin{array}{l}13.250 \text { questionários } \\
\text { enviados, taxa de } \\
\text { resposta foi de } 3 \% \text {. } \\
\text { Estados Unidos. }\end{array}$ & $\begin{array}{l}\text { Os resultados mostram que os investidores percebem que as } \\
\text { informações financeiras auditadas a partir do ano de } 2001 \text { são mais } \\
\text { relevantes, mas menos confiáveis devido à percepção da menor } \\
\text { independência entre as firmas de auditoria e as empresas auditadas. }\end{array}$ \\
\hline $\begin{array}{l}\text { Campbell e } \\
\text { Slack (2008) }\end{array}$ & $\begin{array}{l}\text { Explorar as questões de utilidade } \\
\text { e relevância de divulgações das } \\
\text { notas explicativas dos relatórios } \\
\text { financeiros. }\end{array}$ & $\begin{array}{l}\text { Entrevista semiestruturada } \\
\text { com analistas sell-side com } \\
\text { duração de uma hora. } \\
\text { Realizadas entre o final de } \\
2004 \text { e metade de } 2006 \text {. } \\
\text { Setor Bancário. }\end{array}$ & $\begin{array}{lr}\text { Foram } & 19 \\
\text { entrevistados. } & \text { Reino } \\
\text { Unido. } & \end{array}$ & $\begin{array}{l}\text { Os participantes demonstraram que havia uma crença geral de que } \\
\text { as notas explicativas não eram imediatamente aplicáveis, nem úteis } \\
\text { nas tarefas primárias do sell-side (que é a construção de modelos de } \\
\text { previsão e relatórios para o buy-sider). Apesar disso, os } \\
\text { pesquisadores não conseguiram identificar o uso específico de uma } \\
\text { determinada categoria de divulgação dos relatórios financeiros. O } \\
\text { relatório administração e o relatório socioambiental são irrelevantes. } \\
\text { Já a divulgação dos riscos foi considerada extremamente importante } \\
\text { e os relatórios de governança corporativa geralmente não são lidos, } \\
\text { pois a governança bancária no Reino Unido possui alta taxa de } \\
\text { confiança por parte dos analistas. }\end{array}$ \\
\hline $\begin{array}{l}\text { Zoysa e } \\
\text { Rudkin (2010) }\end{array}$ & $\begin{array}{l}\text { Reportar como os usuários das } \\
\text { demonstrações financeiras } \\
\text { anuais em um mercado } \\
\text { emergente visualizam esses } \\
\text { relatórios. }\end{array}$ & Questionário. & $\begin{array}{l}264 \text { respondentes. Sri } \\
\text { Lanka. }\end{array}$ & $\begin{array}{l}\text { Os resultados revelam que a maioria usa os relatórios anuais para a } \\
\text { obtenção de informações das transações das ações. Apesar do } \\
\text { atraso na publicação e da falta de disponibilidade de acesso público } \\
\text { em geral, a maioria identifica como uma importante fonte de } \\
\text { informação. Em comparação a mercados desenvolvidos, os usuários } \\
\text { do Sri Lanka dependem mais de informações das demonstrações } \\
\text { contábeis do que das fornecidas por corretores, jornais e outros } \\
\text { comentários da mídia. }\end{array}$ \\
\hline $\begin{array}{l}\text { Cascino et al. } \\
(2016)\end{array}$ & $\begin{array}{l}\text { Investigar a utilização da } \\
\text { informação financeira pelos } \\
\text { provedores de capital. }\end{array}$ & $\begin{array}{l}\text { Questionário. Experimento. } \\
\text { Investidores institucionais. }\end{array}$ & $\begin{array}{l}81 \text { participantes de } 16 \\
\text { países. }\end{array}$ & $\begin{array}{l}\text { Os resultados da pesquisa indicaram que o objetivo do uso da } \\
\text { informação importa. Atribuem maior importância para as } \\
\text { informações de resultado. Os participantes informaram que, apesar } \\
\text { de todas as fontes de informação disponíveis hoje em dia, as } \\
\text { demonstrações financeiras continuam sendo as primeiras a serem } \\
\text { utilizadas em suas decisões. Principalmente para aqueles que } \\
\text { pretendem analisar o desempenho gerencial. }\end{array}$ \\
\hline
\end{tabular}

Figura 1. Estudos anteriores sobre percepção dos usuários quanto à relevância da informação contábil

Fonte: Elaborado pelos autores. 
Outro aspecto notado por esses estudos foram algumas preocupações que os usuários possuem acerca das informações financeiras, como a falta de disponibilidade, a divulgação não tempestiva e a deficiência na comunicação, as comumente relatadas nas pesquisas. Percebe-se que são inquietações que estão relacionadas às outras características qualitativas da informação, conforme a estrutura conceitual estabelece, que são a tempestividade e a compreensibilidade.

Os preparadores da informação e os analistas de investimento não acreditam que a melhoria da divulgação seja requisito suficiente para acabar com os problemas da informação financeira (Ho \& Wong, 2001).

Comparados com a literatura internacional, os estudos feitos no Brasil sobre a relevância da informação, com abordagem qualitativa, apresentam-se incipientes e com pouca repercussão acadêmica.

Os resultados encontrados no estudo de Boff, Procianoy e Hoppen (2006) corroboram os estudos internacionais em países emergentes no que se refere à falta de informação externa divulgada pelas empresas. Antunes e Leite (2008) também identificaram que há pouca divulgação dos ativos intangíveis, apesar de a analista de investimento considerar uma conta importante para tomada de decisão, mesmo que de maneira indireta.

A convergência às normas internacionais trouxe uma maior carga de divulgação obrigatória. Os estudos supracitados estavam fora do período de convergência ou ainda no início. Sugerem que essa realidade pode ter mudado com a maturidade das normas internacionais, interpretações e orientações desenvolvidas pelos órgãos reguladores.

No que se refere aos estudos sobre relevância da informação contábil do setor elétrico, foi possível identificar que há uma maior quantidade de pesquisas sobre value relevance para o setor do que a utilização de uma abordagem qualitativa sobre a relevância da informação. Ainda assim, estudos como os de Ribeiro, Macedo e Marques (2012) e o de Gomes (2013) procuraram identificar a importância de indicadores ou de dados contábeis para distintos grupos de usuários da informação. O primeiro estudo foi realizado com credores e o segundo com gestores (usuários internos) que, apesar de não serem o foco deste estudo, também fazem parte dos destinatários da informação contábil. Os resultados corroboram estudos anteriores quanto à informação contábil ser relevante, seja para base de indicadores seja para utilização interna.

\section{METODOLOGIA}

A pesquisa é caracterizada como descritiva. O instrumento de coleta de dados para este estudo foi o questionário disponibilizado online por meio da ferramenta de formulários do Google. Para captar as percepções dos analistas de crédito e dos de investimentos em relação às demonstrações contábeis societárias e regulatórias do setor elétrico brasileiro, fezse necessário realizar uma pesquisa de abordagem qualitativa-quantitativa.

O questionário desta pesquisa foi elaborado com o intuito de compreender como os analistas percebem a utilidade das informações contábeis de uma empresa do setor que é qualificada como referência para as decisões de investimento, manutenção ou desinvestimento. Inclui um conjunto de questões acompanhadas de um modelo de demonstrações financeiras que servirão de base para análise.

Para colocar o participante em uma situação mais próxima da realidade de um analista financeiro especialista no setor de energia elétrica, foram elaborados dois cases com situações que simulam as divergências de classificações contábeis da infraestrutura de uma empresa do setor elétrico. Além disso, foram formatadas demonstrações contábeis com comparativo do modelo societário com o regulatório.

As demonstrações contábeis utilizadas como referência na pesquisa foram preparadas com base em dados de uma empresa privada do setor elétrico que desenvolve atividade de distribuição de energia em um Estado do Brasil. Os dados foram resumidos para viabilizar sua aplicação junto aos respondentes dos questionários em um tempo não superior a uma hora.

As perguntas utilizadas no questionário foram elaboradas a partir do questionário desenvolvido por Cascino et al. (2016). Foram realizadas algumas modificações para 
adequação ao objetivo da presente pesquisa. As questões do instrumento de pesquisa incluem perguntas sobre os seguintes temas: Perfil dos respondentes - com a intenção de conhecer o público alvo (bloco 1); Relevância da Informação Contábil - o propósito desse bloco foi o de captar as percepções quanto às informações financeiras em geral para aqueles respondentes por meio de perguntas fechadas (bloco 2); Contrato de concessão - nessa parte foram apresentados dois casos de registros contábeis da infraestrutura pública para uma concessionária, de acordo com a ICPC 01 . Os exemplos foram elaborados visando a simular a situação de uma transmissora e uma distribuidora de energia elétrica, respectivamente (bloco 3); e, por fim, Relevância da Informação Contábil Regulatória - com o intuito de identificar o que esse grupo de usuários acredita ser importante para suas análises, no que se refere às empresas de distribuição de energia elétrica (bloco 4). No último bloco as percepções foram coletadas por meio de uma análise simplificada das demonstrações societárias e regulatórias de uma empresa do setor elétrico de distribuição e também através de algumas perguntas fechadas e apenas uma aberta.

Para mensurar a percepção dos respondentes foi adotada uma escala likert de sete itens com a seguinte designação: (a) discordo totalmente; (b) discordo em grande parte; (c) discordo em parte; (d) neutro; (e) concordo em parte; (f) concordo em grande parte e (g) concordo totalmente. A cada uma dessas respostas foi atribuído um número em uma escala ordinal de um a sete. Com base nesta escala ordinal foi possível aplicar testes estatísticos não paramétricos, como normalmente aplicado em estudos científicos que utilizam questionários.

Quanto à identificação dos profissionais de mercado, foram analisadas 14 empresas do setor de energia elétrica, as quais divulgavam, em seu site de Relacionamento com Investidores $(\mathrm{RI})$, os contatos (e-mail e telefone) dos analistas financeiros indicados pela empresa. No total, foram encontrados 224 nomes de analistas financeiros. Excluídos os nomes que não tinham dados para contato e os duplicados, a população do trabalho reduziuse a 56 analistas financeiros "especialistas" no setor elétrico. A amostra final compreendeu 26 analistas financeiros (46,4\% do total) que responderam aos questionários enviados.

Esses profissionais foram selecionados por acessibilidade e conveniência, e ainda porque a literatura sugere que esse tipo de analista normalmente utiliza as informações contábeis em seu processo decisório. Adicionalmente, apesar de já existir um grande volume de pesquisas no âmbito da utilidade da informação, não foram encontrados na pesquisa de referencial teórico expressivos estudos na literatura local que procurassem identificar a percepção dos analistas financeiros de um setor com peculiaridades contábeis e regulatórias como o de energia elétrica.

A pesquisa utilizou ferramentas de estatística descritiva das frequências, o teste Quiquadrado e o teste não paramétrico de Mann-Whitney para duas amostras independentes.

\section{ANÁLISE DOS RESULTADOS}

$\mathrm{Na}$ primeira parte do questionário, os respondentes forneceram informações sobre idade, gênero, principal formação acadêmica, atual ocupação, tempo de atuação, quantidade de empresas analisadas por ano, tipo de analista, tipo de empresa em que trabalha e se utiliza a informação financeira para compor suas análises. Para melhor apresentar os dados, foram elaboradas duas tabelas que resumem cada parte do questionário. A primeira (Tabela 1) trata do perfil do respondente.

A amostra final foi composta por 26 analistas financeiros, listados pelas empresas do setor elétrico em seus sites de Relacionamento com Investidor, representando $46,4 \%$ da população identificada. $65 \%$ da amostra era formada por homens e $35 \%$ por mulheres. Com base no teste qui-quadrado realizado é possível afirmar que não existe diferença estatisticamente significativa entre a proporção de homens e mulheres da amostra em relação à população analisada $[\mathrm{X} 2=0,813(p$-value $>0,10)]$. $\mathrm{O}$ resultado desse teste estatístico permite concluir que a composição de gênero da amostra não apresenta distorções em relação ao perfil da população analisada. 
Tabela 1

Perfil do Respondente - Dados Básicos

\begin{tabular}{|c|c|c|}
\hline \multicolumn{3}{|c|}{ Painel A - Gênero } \\
\hline & \multicolumn{2}{|c|}{ Amostra $(\mathrm{N}=26)$} \\
\hline & Quantidade & $\%$ \\
\hline Feminino & 9 & $35 \%$ \\
\hline Masculino & 17 & $\underline{65 \%}$ \\
\hline Total & 26 & $100 \%$ \\
\hline
\end{tabular}

Painel B - Formação acadêmica

Economia

Engenharia

Ciências Contábeis

Administração

\begin{tabular}{cc} 
Quantidade & $\%$ \\
\hline 12 & $46 \%$ \\
9 & $35 \%$ \\
3 & $12 \%$ \\
$\underline{2}$ & $\underline{8 \%}$ \\
26 & $100 \%$
\end{tabular}

\begin{tabular}{ccc} 
População $(\mathrm{N}=56)$ & $\begin{array}{c}\text { Teste } \mathrm{X}^{2} \\
(p \text {-value })\end{array}$ \\
\hline Quantidade & $\%$ & 0,813 \\
$\underline{14}$ & $25 \%$ & $(0,367)$ \\
56 & $\underline{75 \%}$ &
\end{tabular}

Painel C - Tipo de analista

Investimento 'buy side'

Quantidade

$\%$

Investimentos 'sell side'

Crédito e similares

Analista de Rating
$8 \%$

$42 \%$

$4 \%$

$100 \%$

Nota. $\mathrm{n}=26$ respondentes.

Fonte: Elaborada pelos autores, com base nos questionários recebidos.

De acordo com o Painel $\mathrm{C}$, da Tabela 1, as atividades profissionais predominantes nas respostas têm o propósito de "investimentos buy side" e "crédito e similares". Compõem 46\% e $42 \%$, respectivamente. Ressalta-se que para as análises foram formados dois grupos distintos. Os respondentes foram classificados como analista de investimento ou analista de crédito e similares (analista de rating), representando 54\% e $46 \%$ do total, respectivamente.

A Tabela 2, a seguir, apresenta os valores médios (ranking médio conforme escala likert de sete itens) calculados com base na frequência de resposta dos dois grupos de analistas, de acordo com sua formação e o valor médio do total dos respondentes e, além disso, os resultados do teste não paramétrico para duas amostras independentes (tipo de analista) dos indicadores evidenciados no Painel $A$.

O Painel A da Tabela 2 apresenta os índices médios encontrados para os indicadores econômico-financeiros. Em linhas gerais, os indicadores de Dívida Líquida/EBITDA e de Dívida Líquida/Patrimônio Líquido apresentaram maiores graus de concordância, enquanto os indicadores com base em contas patrimoniais foram os que apresentaram um menor nível de similaridade das respostas, variando entre 4,1 a 4,5 . Os índices na escala 4 são considerados "neutros", ou seja, para interpretação da pesquisa são "indiferentes" para as análises dos respondentes.

O Painel B da Tabela 2 revela que a maioria dos respondentes admite que a Demonstração de Resultado, o Balanço Patrimonial, a Demonstração de Fluxo de Caixa e as Notas Explicativas são totalmente relevantes para suas análises. Para essas demonstrações, o ranking médio variou entre 6,9 e 7,0.

Os resultados apresentados são consistentes com os encontrados por Ohara (2014), que analisou a diferença dos indicadores financeiros calculados com base na informação das duas sistemáticas contábeis das principais empresas do setor elétrico e constatou que indicadores como "dívida líquida/EBITDA", "resultado líquido/patrimônio líquido" e "resultado líquido/ receita" apresentam diferenças significativas devido à divergência dos tratamentos societários e regulatórios.

Considerando os resultados do teste não paramétrico, é possível observar que não há diferença estatisticamente significante quanto à percepção sobre a relevância da maioria dos indicadores econômicos financeiros entre os analistas de investimento e os de crédito e similares [ $p$-value $>0,10]$. Apenas para o índice do ativo circulante/passivo [X2 $=37,50$ e $p$ value $\neg<0,10$ ], observou-se que os analistas de crédito atribuem mais importância que os analistas de investimento, 5,4 e 4,9, respectivamente. 
Tabela 2

Relevância da Informação Contábil - Indicadores Financeiros, Demonstrações Financeiras e Contas Contábeis - por tipo de analista

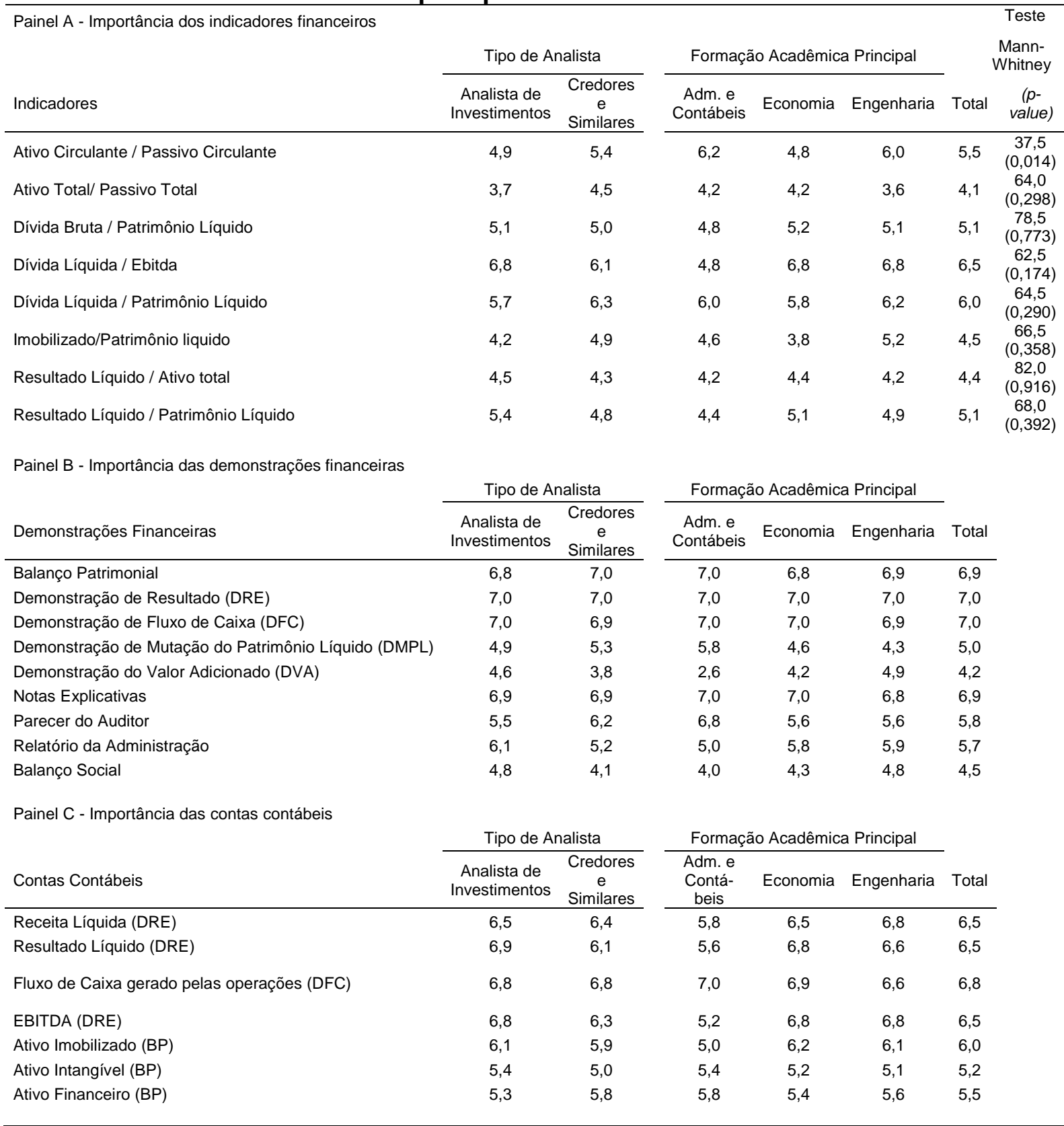

Nota. 26 respondentes.

(a) Os valores médios indicados foram apurados conforme escala likert de sete itens. (b) (1) Discordo totalmente; (2) Discordo em grande parte; (3) discordo em parte; (4) Neutro; (5) Concordo em parte; (6) Concordo em grande parte e (7) Concordo totalmente.

Fonte: Elaborada pelos autores.

A fim de captar a opinião dos respondentes sobre a forma de registro contábil da infraestrutura de bens de concessão, foram elaborados dois exemplos (similares ao da ICPC 01) quanto à contabilização da infraestrutura de uma rede de transmissão e o outro de uma rede de distribuição de energia elétrica. A interpretação ICPC 01, juntamente com a orientação OCPC 05, estabelecem que a infraestrutura de concessão que estiver no escopo da norma deverá ser registrada como um ativo financeiro e/ou ativo intangível, conforme descrito no referencial deste estudo.

A Tabela 3 apresenta uma síntese da preferência da forma de apresentação das informações societárias e regulatórias por parte dos analistas de investimento e analistas de crédito. Evidencia que apenas $38 \%$ dos respondentes optaram por uma divulgação separada 
das demonstrações societárias e regulatórias, que é a forma atual de fazê-la. A demonstração societária é arquivada na CVM e a regulatória na ANEEL. A maioria dos respondentes optou por ter uma demonstração evidenciando o comparativo do societário e regulatório ou por ter uma nota explicativa na demonstração societária com a conciliação do Patrimônio Líquido e do Lucro Líquido, representando 38\% e 19\%, respectivamente. Apenas um respondente com formação em Ciências Contábeis acredita que a divulgação deveria ser apenas da demonstração financeira societária.

Tabela 3

\section{Preferência dos respondentes pela forma de divulgação das informações}

Painel A - Quantidade de respondentes por tipo de analista

\begin{tabular}{lccc} 
Divulgação & $\begin{array}{c}\text { Analista de } \\
\text { Investimentos }\end{array}$ & $\begin{array}{c}\text { Credores } \\
\text { Similares }\end{array}$ & Total \\
\hline Societária & 0 & 1 & 1 \\
Conciliação & 3 & 2 & 5 \\
Separada & 5 & 5 & 10 \\
Comparativa & 6 & 4 & 10 \\
\cline { 2 - 4 } \multicolumn{1}{c}{ Total } & 14 & 12 & 26
\end{tabular}

\begin{tabular}{|c|c|c|}
\hline $\begin{array}{c}\text { Analista de } \\
\text { Investimentos }\end{array}$ & $\begin{array}{c}\text { Credores } \\
\text { e } \\
\text { Similares }\end{array}$ & Total \\
\hline $0 \%$ & $4 \%$ & $4 \%$ \\
\hline $12 \%$ & $8 \%$ & $19 \%$ \\
\hline $19 \%$ & $19 \%$ & $38 \%$ \\
\hline $23 \%$ & $15 \%$ & $38 \%$ \\
\hline $54 \%$ & $46 \%$ & $100 \%$ \\
\hline
\end{tabular}

Painel B - Quantidade de respondentes por formação profissional

\begin{tabular}{lcccc} 
Divulgação & $\begin{array}{c}\text { Adm. e } \\
\text { Contábeis }\end{array}$ & Economia & Engenharia & Total \\
\hline Societária & 1 & 0 & 0 & 1 \\
Conciliação & 0 & 2 & 3 & 5 \\
Separada & 2 & 6 & 2 & 10 \\
Comparativa & 2 & 4 & 4 & 10 \\
\cline { 2 - 5 } & 5 & 12 & 9 & 26
\end{tabular}

\begin{tabular}{cccc}
$\begin{array}{c}\text { Adm. e } \\
\text { Contábeis }\end{array}$ & Economia & Engenharia & Total \\
\hline $4 \%$ & $0 \%$ & $0 \%$ & $4 \%$ \\
$0 \%$ & $8 \%$ & $12 \%$ & $19 \%$ \\
$8 \%$ & $23 \%$ & $8 \%$ & $38 \%$ \\
$8 \%$ & $15 \%$ & $15 \%$ & $38 \%$ \\
\hline $20 \%$ & $46 \%$ & $35 \%$ & $100 \%$
\end{tabular}

Nota. (a) Tanto a demonstração societária quanto a regulatória devem ser divulgadas separadamente; (b) Comparativo das duas demonstrações (societária e regulatória) deveria ser divulgado em um relatório integrado; (c) Nota explicativa de conciliação entre o Patrimônio Líquido e Lucro Líquido da contabilidade societária e regulatória; (d) As informações regulatórias não deveriam ser publicadas, apenas disponibilizadas apara o órgão regulador competente. ( $n=26$ respondentes).

Fonte: Elaborada pelos autores.

No painel A da Tabela 3, percebe-se que todos os "Analistas de Investimentos" preferem a divulgação de ambas as informações. Os resultados sugerem que há uma tendência entre os analistas em preferir essa informação de maneira mais detalhada, considerando que a divulgação separada e comparativa tende a ser mais informativa do que a divulgação da conciliação das contas impactadas pela divergência dos modelos contábeis ou apenas das demonstrações financeiras societárias.

Para analisar as preferências sobre o formato da demonstração de resultado, se regulatória ou societária, os respondentes foram questionados sobre qual dos dois formatos consideram mais adequados para suas análises. O resumo das respostas consta da Tabela 4.

Tabela 4

Preferência do formato da Demonstração de Resultados

\begin{tabular}{|c|c|c|c|c|c|c|c|}
\hline & $\begin{array}{c}\text { Analista de } \\
\text { Investimentos }\end{array}$ & $\begin{array}{c}\text { Credores e } \\
\text { Similares }\end{array}$ & Total & $\begin{array}{c}\text { Analista de } \\
\text { Investimentos }\end{array}$ & $\begin{array}{c}\text { Credores e } \\
\text { Similares } \\
\end{array}$ & Total & $\begin{array}{c}\text { Teste } X^{2}(p- \\
\text { value) }\end{array}$ \\
\hline Regulatória & 11 & 4 & 15 & $42 \%$ & $15 \%$ & $58 \%$ & 5,418 \\
\hline Societária & 3 & 8 & 11 & $12 \%$ & $31 \%$ & $42 \%$ & 0,02 \\
\hline Total & 14 & 12 & 26 & $54 \%$ & $46 \%$ & $100 \%$ & \\
\hline
\end{tabular}

Nota. $\mathrm{n}=26$ respondentes.

Fonte: Elaborada pelos autores.

A Tabela 4 revela que, embora a maioria dos respondentes prefira a DRE Regulatória para compor suas análises, num total de $58 \%$ da amostra, o modelo de DRE societária também apresentou um alto grau de preferência (42\%) dos respondentes. As evidências estatísticas sugerem que os analistas de investimentos apresentam maior preferência pela DRE regulatória, enquanto os analistas de crédito optaram pela demonstração de resultado societária $[\mathrm{X} 2=5,418(p$-value $<0,10)]$. 
Para melhor compreender as preferências dos participantes, esses justificaram suas escolhas de maneira dissertativa. O resumo dos resultados encontrados é reportado no Figura 2. Examinando as justificativas dos respondentes que escolheram a DRE regulatória, é possível notar que há uma tendência das respostas no que diz respeito à sua importância: a) geração do fluxo de caixa e b) discriminação dos custos da Parcela A. Já aqueles que optaram pelo modelo societário tenderam a responder que na demonstração de resultado regulatória há informação em excesso.

Corroborando o resultado do teste estatístico, em que é possível verificar que há um maior interesse dos analistas de investimentos na DRE regulatória, em 9 das 11 justificativas o fluxo de caixa é citado como motivo da preferência. Já os analistas de crédito ou similares, que preferem, em sua maioria, a DRE societária, comentaram que há excesso de informação na DRE regulatória.

\begin{tabular}{|c|c|}
\hline $\begin{array}{l}\text { Painel A - Analistas de Investimentos } \\
\text { Regulatório } \\
\text { - "Interesse na geração de caixa efetiva" (Economia); } \\
\text { - Mais clareza dos dados da concessão para além da volatilidade de } \\
\text { curto prazo" (Engenharia); } \\
\text { - "Melhor informação para cálculo correto dos fluxos de caixa da } \\
\text { empresa" (Engenharia); } \\
\text { - "O efeito caixa está melhor refletido nas demonstrações regulatórias, } \\
\text { além delas discriminarem o que é custo de Parcela A e custo de Parcela } \\
\text { B" (Economia); } \\
\text { - "O LL regulatório não tem efeitos não caixa como, por ex, a } \\
\text { reavaliação do Ativo Financeiro (item não caixa e não operacional da } \\
\text { distribuidora) e evidencia também as diferenças entre depreciação } \\
\text { contábil e regulatória (item que impacta quase todas as contas)" } \\
\text { (Economia); } \\
\text { - "Os dois são importantes, mas para termos de análise do Fluxo de } \\
\text { Caixa o regulatório fornece maiores detalhes de informações" } \\
\text { (Economia); } \\
\text { - "Porque há menos lançamentos contábeis e retratam melhor a real } \\
\text { geração de caixa da companhia" (Economia); } \\
\text { - "Reflete de maneira mais adequada a geração de caixa do período" } \\
\text { (Economia); } \\
\text { - "Reflete melhor o economics do negócio" (Engenharia); } \\
\text { - "Regulatório facilita entendimento de rentabilidade recorrente dada às } \\
\text { oscilações de Parcela A no formato societário" (Economia); } \\
\text { - "Relação mais próxima com o FCF" (Economia). }\end{array}$ & $\begin{array}{l}\text { Societário } \\
\text { - "Mais próximo ao fluxo de caixa real" } \\
\text { (Engenharia); } \\
\text { - "Para fins de análise de equity o resultado } \\
\text { societário é mais importante" (Economia); } \\
\text { - "Reflete a verdadeira saúde financeira da cia" } \\
\text { (Engenharia); } \\
\text {-"Societário representa a competência e consegue- } \\
\text { se ver o recebimento (ou não) e o financiamento } \\
\text { (ou não) dos direitos e deveres no Balanço } \\
\text { Patrimonial" (Adm. e Contábeis). }\end{array}$ \\
\hline 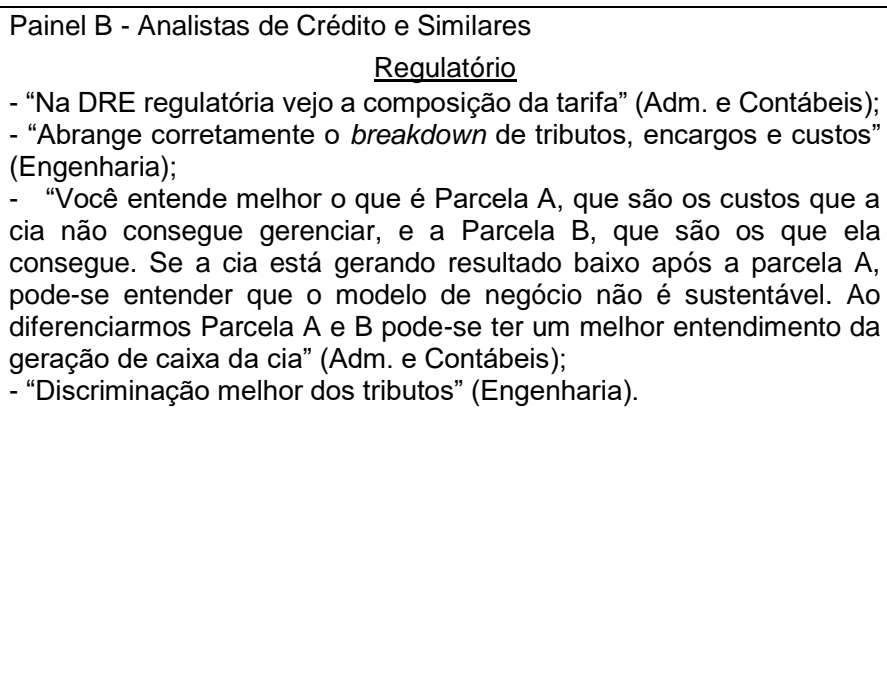 & $\begin{array}{l}\text { Societário } \\
\text { - "Demonstração base para dividendos" (Adm. e } \\
\text { Contábeis); } \\
\text { - "Porque o regulatório depende de decisões do } \\
\text { poder concedente" (Economia); } \\
\text { - "As informações da DRE Regulatória são } \\
\text { complementares na análise, trazendo dados do } \\
\text { desempenho operacional, desta forma a Societária } \\
\text { reflete o econômico-financeiro da Companhia, } \\
\text { sendo mais adequado para as análises de risco de } \\
\text { crédito" (Adm. e Contábeis); } \\
\text { - "Regulatório é polúdo e pode variar com } \\
\text { mudanças regulatórias" (Economia); } \\
\text { - "Tende a demostrar melhor o resultado da } \\
\text { empresa além de ser mais limpo" (Engenharia). } \\
\text { - "Não me interesso na separação entre as contas. } \\
\text { Excesso de informação" (Economia); } \\
\text { - "O formato de custos/despesas é o mais } \\
\text { compreensível para avaliar a empresa em um } \\
\text { primeiro momento" (Engenharia). }\end{array}$ \\
\hline
\end{tabular}

Figura 2. Análise Qualitativa dos Dados ( $\mathrm{n}=26$ respondentes)

Fonte: Elaborado pelos autores. 
Ainda no quesito divulgação, os participantes foram perguntados se a data de divulgação da demonstração regulatória posterior à data da divulgação societária traz prejuízo para suas análises, a fim de identificar se os analistas de investimento ou de crédito percebem que as apresentações em datas distintas afetam suas análises. A Tabela 5 demonstra 0 resumo dos resultados para tal questionamento.

A Tabela 5 revela que, em média, os participantes concordam que há um prejuízo para suas análises face à divulgação da informação regulatória ser posterior à informação societária, representando um total de $74 \%$ de concordância com tal prejuízo. Segregando por tipo de analista verifica-se que $27 \%$ são analistas de investimento, os quais concordam que perdem informação com a divulgação em data posterior.

Tabela 5

Percepção sobre prejuízo nas análises devido à diferença de data de divulgação

\begin{tabular}{|c|c|c|c|c|c|c|}
\hline & \multicolumn{2}{|c|}{ Tipo de Analista } & \multicolumn{3}{|c|}{ Formação Acadêmica Principal } & \multirow[b]{2}{*}{ Total } \\
\hline & Analista de Investimentos & Credores e Similares & $\begin{array}{l}\text { Adm. ou } \\
\text { Contábeis }\end{array}$ & Economia & Engenharia & \\
\hline Discordo totalmente & $4 \%$ & - & - & $4 \%$ & - & $4 \%$ \\
\hline $\begin{array}{l}\text { Discordo em Grande } \\
\text { Parte }\end{array}$ & $4 \%$ & - & - & $4 \%$ & - & $4 \%$ \\
\hline Discordo em Parte & - & $4 \%$ & - & - & $4 \%$ & $4 \%$ \\
\hline Neutro & $4 \%$ & $12 \%$ & $8 \%$ & $8 \%$ & - & $15 \%$ \\
\hline Concordo em Parte & - & $12 \%$ & $4 \%$ & $4 \%$ & $4 \%$ & $12 \%$ \\
\hline $\begin{array}{l}\text { Concordo em Grande } \\
\text { Parte }\end{array}$ & $15 \%$ & $15 \%$ & $4 \%$ & $12 \%$ & $15 \%$ & $31 \%$ \\
\hline Concordo totalmente & $27 \%$ & $4 \%$ & $4 \%$ & $15 \%$ & $12 \%$ & $31 \%$ \\
\hline Ranking Médio & 5,7 & 5,1 & 5,2 & 5,2 & 5,9 & 5,4 \\
\hline \multirow[t]{2}{*}{ Teste de Mann Whitney } & & $x^{2}$ & \multicolumn{4}{|c|}{$p$-value } \\
\hline & & 49,0 & \multicolumn{4}{|c|}{$(0,063)$} \\
\hline
\end{tabular}

Nota. $\mathrm{n}=26$ respondentes.

Fonte: Elaborada pelos autores.

Com base nos resultados encontrados no teste estatístico, pode-se constatar que os analistas de investimentos e os analistas de crédito e similares percebem de forma distinta o prejuízo em suas análises devido à divulgação das demonstrações regulatórias em data posterior $[p$-value $<0,10]$. Ponderando os valores médios encontrados e o resultado do teste estatístico é possível notar que os analistas de investimento têm maior concordância que os analistas de crédito no que diz respeito à existência de perda informacional para suas análises, em função da diferença de data de divulgação das demonstrações societária e regulatória.

A Tabela 6 evidencia o grau de percepção dos respondentes sobre as contas contábeis particulares do setor de energia elétrica que, em sua grande maioria, compõem a demonstração de resultado, além de duas contas do balanço patrimonial. Há contas que são vistas em ambos os modelos como também há contas apresentadas apenas em um dos tratamentos contábeis. Todas elas estão relacionadas ou à ICPC 01 ou ao Manual de Contabilidade Regulatória do Setor Elétrico.

Examinando a Tabela 6, é possível observar que há uma concordância de que as contas referentes à composição da tarifa são relevantes para análises das empresas do setor em questão. Contas como "ativo regulatório", "passivo regulatório", "recomposição tarifária Parcela A" e "custos da Parcela A" obtiveram um nível médio entre 6,0 e 6,4 de concordância. A conta de "custos de construção", que é de caráter puramente societário, recebeu a menor pontuação média $(3,7)$ entre os analistas de investimentos.

Os resultados encontrados no teste não paramétrico sugerem que é possível observar que os analistas de investimento consideram as contas ativo regulatório (BP), passivo regulatório (BP), disponibilidade de rede $(\mathrm{R})$ mais relevantes que os analistas de crédito [ $p$ value $<0,10]$, com exceção da conta "custo de construção". Os analistas de investimento 
tendem a discordar que essa conta seja relevante para compor suas análises e os analistas de crédito e similares parecem concordar que são importantes.

Tabela 6

Importância das contas contábeis na DRE regulatória

\begin{tabular}{|c|c|c|c|c|c|c|c|}
\hline \multirow[b]{2}{*}{ Contas Contábeis } & \multicolumn{2}{|c|}{ Tipo de Analista } & \multicolumn{3}{|c|}{ Formação Acadêmica Principal } & \multirow[b]{2}{*}{ Total } & \multirow{2}{*}{$\begin{array}{c}\text { Teste } \\
\text { Mann- } \\
\text { Whitney } \\
\text { (p-value) }\end{array}$} \\
\hline & $\begin{array}{c}\text { Analista de } \\
\text { Investimentos }\end{array}$ & $\begin{array}{c}\text { Credores e } \\
\text { Similares }\end{array}$ & $\begin{array}{l}\text { Adm. e } \\
\text { Contá- } \\
\text { beis }\end{array}$ & Economia & Engenharia & & \\
\hline Ativo Regulatório & 6,9 & 5,8 & 5,4 & 6,5 & 6,8 & 6,4 & $\begin{array}{c}43,0 \\
(0,013) \\
49,5\end{array}$ \\
\hline Passivo Regulatório & 6,7 & 5,8 & 5,4 & 6,4 & 6,7 & 6,3 & $(0,042)$ \\
\hline Recomposição Tarifária Parcela A & 6,5 & 6,0 & 6,0 & 6,3 & 6,4 & 6,3 & $\begin{array}{c}(0,859) \\
68,5\end{array}$ \\
\hline Fornecimento de Energia & 6,1 & 5,7 & 5,0 & 5,9 & 6,4 & 5,9 & $\begin{array}{c}(0,390) \\
51,5\end{array}$ \\
\hline Disponibilidade de Rede & 6,0 & 5,2 & 4,6 & 5,8 & 6,0 & 5,6 & $\begin{array}{c}(0,082) \\
84,0\end{array}$ \\
\hline Custos da Parcela A & 6,2 & 5,8 & 5,8 & 6,0 & 6,2 & 6,0 & $\begin{array}{c}(1,000) \\
52,0\end{array}$ \\
\hline Custos de Construção & 3,7 & 5,4 & 4,6 & 2,8 & 6,0 & 4,5 & $\begin{array}{c}(0,093) \\
74,5\end{array}$ \\
\hline Despesas Antecipadas - CVA & 5,9 & 5,6 & 4,4 & 5,6 & 6,4 & 5,8 & $\begin{array}{c}(0,610) \\
75,0\end{array}$ \\
\hline Tributos Diferidos & 5,2 & 5,0 & 3,6 & 5,1 & 5,4 & 5,1 & $\begin{array}{c}(0,635) \\
61,0\end{array}$ \\
\hline Remuneração do Ativo Financeiro & 4,8 & 6,0 & 6,0 & 4,8 & 6,2 & 5,3 & $(0,205)$ \\
\hline
\end{tabular}

Nota. $\mathrm{n}=26$ respondentes.

Fonte: Elaboradas pelos autores.

Os resultados evidenciaram que os analistas de investimentos e os de crédito e similares utilizam a informação contábil e que, em geral, consideram as demonstrações financeiras importantes para compor suas análises. A demonstração de resultado (DRE), o balanço patrimonial (BP) e a demonstração de fluxo de caixa (DFC) foram percebidos como os mais importantes para esses analistas, confirmando os resultados encontrados em estudos anteriores (vide, por exemplo, Cascino et al., 2016).

As contas de resultado são avaliadas como mais relevantes diante das contas patrimoniais. Adicionalmente o fluxo de caixa gerado pelas operações, evidenciado na DFC, foi considerado muito importante pelos respondentes. Quanto aos indicadores, destaca-se o índice da "Dívida Líquida/EBITDA", que, juntamente com a "Dívida Líquida/Patrimônio Líquido", foram considerados relevantes para as análises dos participantes.

Considerando que os participantes atribuíram uma maior relevância à $D R E$, à DFC e ao EBITDA, é possível presumir que os analistas de investimentos e os de crédito utilizam a informação com o papel de estimar geração de fluxo de caixa futuro, uma vez que estão atribuindo uma importância maior para o desempenho financeiro (lucratividade) e para contas (e índices) que são utilizadas para analisar a capacidade de geração de caixa da empresa, a fim de pagar suas dívidas. Corroboram os achados na pesquisa de Cascino et al. (2016), o qual demonstrou que a procura e o uso da informação financeira são feitos para atender à necessidade de prever ou estimar fluxos de caixa e que os itens patrimoniais não são tão relevantes em razão da função da informação ser mais confirmatória do que preditiva.

Tanto os analistas investigados nesta pesquisa quanto os do estudo de Cascino et al. (2016) avaliaram o EBITDA como de alta relevância para suas análises, pois é uma medida de rápido acesso da geração de caixa da empresa.

Os participantes foram questionados sobre a relevância de contas específicas do setor de energia elétrica para suas análises. Os resultados evidenciaram que contas como o ativo regulatório, passivo regulatório, recomposição tarifária - parcela A e custos da parcela A foram consideradas importantes para os participantes.

Anteriormente à orientação OCPC 08, as empresas do setor elétrico não podiam reconhecer as contas regulatórias como ativos e passivos regulatórios (patrimoniais) e, consequentemente, as contas de resultado vinculadas a elas (fornecimento de energia, disponibilidade de rede e custos e encargos da parcela A), nas demonstrações societárias. $O$ IASB afirmava que tais ativos e passivos não possuíam as características estabelecidas na 
estrutura conceitual para serem reconhecidos como ativo ou passivo. Com a adoção do OCPC 08 e 0 aditamento dos contratos, as empresas passaram a ter a garantia do poder concedente e puderam reconhecer na demonstração societária tais valores, considerados importantes para revisão da tarifa de energia. As contas do ativo e passivo regulatório, agora registradas na demonstração societária, foram consideradas importantes para as análises desses respondentes.

Analisando os dois grupos, é possível verificar que a divulgação da demonstração regulatória em data posterior à da demonstração societária causa prejuízo na análise de ambos os tipos de analistas. Tal prejuízo é percebido como maior pelos analistas de investimentos. Essas evidências corroboram os resultados da preferência da demonstração de resultado, em que os analistas de investimentos consideram a DRE regulatória como mais adequada para atender às necessidades de suas análises.

Os resultados sugerem que os analistas de crédito possivelmente já possuem modelos de análises padronizados. Provavelmente por esse motivo não atribuem tanta relevância para contas e DRE regulatória e não percebem a perda informacional na divulgação em datas distintas, uma vez que há indícios de que as informações societárias já atendem a seus modelos padronizados. Apesar disso, os analistas de crédito consideram em parte a informação regulatória como relevante e as evidências sugerem que são utilizadas como informações complementares nas análises realizadas pelas empresas do setor de energia elétrica.

Os resultados também revelam que apenas $38 \%$, menos da metade, dos participantes acreditam que a melhor forma de divulgação é a formatação atual, demonstrações societárias e regulatórias separadas. Esses resultados sugerem uma possível necessidade de repensar a forma da divulgação das informações societárias e regulatórias das empresas de energia. Adicionalmente, é possível sugerir que as duas demonstrações são utilizadas, visto que somente um respondente optou por divulgar apenas a demonstração societária. A maioria dos participantes escolheu a demonstração de resultado regulatória como mais adequada para compor suas análises.

Ainda que mais da metade dos respondentes concordem que a divulgação das informações em datas diferentes podem causar algum prejuízo em suas análises, não há uma considerável quantidade de participantes que tenha optado por uma divulgação das informações em formato comparativo ou uma nota de conciliação de ambas as abordagens (regulatória e societária) nas demonstrações financeiras, elaboradas de acordo com as normas de contabilidade vigentes no país. Esses seriam os dois tipos de divulgação em formatação diferente da atual e que contemplam informações societárias e regulatórias em uma única data de divulgação, o que revela que não há um consenso entre os participantes, de como deveriam ser divulgadas as demonstrações, de maneira que amenizassem a perda causada por divulgação em diferentes datas.

\section{CONCLUSÃO}

Esse estudo teve como objetivo analisar as percepções dos analistas financeiros e de crédito quanto à utilidade das informações contábeis societárias e regulatórias das empresas do setor de energia elétrica.

Para atingir o objetivo foi utilizado um questionário como instrumento de coleta de dados. A população foi identificada por meio das informações disponíveis nos sites das empresas de energia elétrica, que indicam profissionais que realizam análises sobre elas. Dos 56 profissionais identificados, 26 responderam a este estudo. Traçado o perfil desses participantes, criaram-se dois grupos: os analistas de investimento e os analistas de crédito e similares.

Os resultados evidenciaram que: i) os itens da demonstração de resultado são mais relevantes que os itens do balanço patrimonial; ii) os analistas de investimento consideram a DRE regulatória mais adequada para suas análises do que os analistas de crédito e similares; iii) a percepção do prejuízo para a análise, devido ao atraso na divulgação das demonstrações regulatórias, foi maior para os analistas de investimento do que para os analistas de crédito e 
iv) o atual formato de divulgação (uma demonstração contábil societária e outra regulatória) das informações financeiras das empresas de energia elétrica não é considerado o ideal para os analistas financeiros.

Em linha com a literatura existente, os achados deste estudo confirmam que as demonstrações financeiras são utilizadas pelos analistas financeiros e que as informações de resultado são mais importantes do que as informações patrimoniais, principalmente para os analistas que possuem objetivo de avaliação dos fluxos de caixa das empresas. Por esse motivo, os analistas de investimento acreditam que a demonstração de resultado regulatória forneça a eles uma informação mais adequada dos resultados operacionais das empresas do setor de energia elétrica do que a demonstração de resultado societária. Adicionalmente, os analistas de investimento percebem que a divulgação em datas diferentes cause-lhes um certo prejuízo informacional.

Independentemente do tipo de analista, a maioria dos respondentes não parece estar satisfeita com o atual formato de divulgação das demonstrações financeiras societárias e regulatórias, visto que acreditam que deveria haver outro tipo de formatação para tais informações. Embora a formatação atual seja separada, uma com arquivamento na CVM e outra na ANEEL, há empresas, como a Transmissora Aliança de Energia Elétrica S.A. (TAESA), que apresentam seus resultados (em uma apresentação voluntária) aos investidores com o formato comparativo das duas demonstrações. Sugere que pode existir uma demanda por esse tipo de divulgação por parte dos usuários externos da informação.

Os resultados encontrados nesta pesquisa podem ser importantes para que os reguladores avaliem uma melhor forma de divulgação das demonstrações societárias e regulatórias pelas empresas do setor elétrico, sem causar prejuízos informacionais para os usuários externos. Outra contribuição do estudo foi evidenciar o que é considerado relevante por parte dos analistas indicados por empresas do setor elétrico, a fim de auxiliar na formatação de normas ou deliberações (como a deliberação no 727/2014 da CVM) que propõem a redução da quantidade de informação divulgada nos relatórios financeiros.

Além das contribuições práticas, o estudo colabora com o desenvolvimento da literatura da relevância da informação contábil, uma vez que apresenta constatações sobre um grupo de usuários específicos que possuem percepções similares às já encontrados em trabalhos anteriores.

Destaca-se que as percepções dos usuários das demonstrações financeiras que participaram deste estudo são pessoais e não representam a totalidade das percepções dos entrevistados. Naturalmente, as pesquisas qualitativas baseadas em questionários são de caráter subjetivo e dependem da compreensão do respondente do instrumento de pesquisa.

Como sugestão de pesquisas futuras, recomenda-se aprofundar o conhecimento da relevância da informação contábil, por meio de estudos que avaliem a utilização dessas informações por parte de outros grupos de usuários ou em outros segmentos econômicos que apresentem demonstrações contábeis regulatórias.

\section{REFERÊNCIAS}

Agência Nacional de Energia Elétrica (2010). Resolução Normativa $n^{\circ}$ 396, de 23 de fevereiro de 2010. Recuperado de http://www.aneel.gov.br/

Agência Nacional de Energia Elétrica (2014). Resolução Normativa $n^{\circ}$ 605, de 11 de março de 2014. Recuperado de http://www.aneel.gov.br/

Antunes, M. T. P., \& Leite, R. S. (2008). Divulgação de informações sobre ativos intangíveis e sua utilidade para analistas de investimentos. Revista Universo Contábil, 4(4), 22-38.

Bartlett, S. A., \& Chandler, R. A. (1997). The corporate report and the private shareholder: Lee and Tweedie 20 years on. British Accounting Review, 29, 245-61.

Boff, L. H., Procianoy, J. L., \& Hoppen, N. (2006). O uso de informações por analistas de investimento na avaliação de empresas: à procura de padrões. RAC, 10(4), 169-192. 
Bouwman, M. J., Frishkoff, P., \& Frishkoff, P. A. (1995). The relevance of GAAP-based information: A case study exploring some uses and limitations. Accouting Horizons, 4(9), 22-47.

Lei $n^{\circ}$ 11.638, de 28 de dezembro de 2007. Altera e revoga dispositivos da Lei no 6.404/76, e dá outras providências. Recuperado de http://www.planalto.gov.br

Campbell, D., \& Slack, R. (2008). Narrative reporting: analysts' perceptions of its value and relevance. London: Association of Chartered Certified Accountants, Report n. 104.

Cascino, S., Clatworthy, M., Osma, B. G; Gassen, J., Imam, S., \& Jeanjean, T. (2016). Professional investors and the decision usefulness of financial reporting. Institute of Chartered Accountants of Scotland (ICAS) and European Financial Reporting Advisory Group (EFRAG).

Comitê de Pronunciamentos Contábeis (2012). Estrutura conceitual - CPC 00 R1. Recuperado de http://www.cpc.org.br/pdf/CPC 00_R1.pdf

Comitê de Pronunciamentos Contábeis (2009). Interpretação técnica ICPC 01 - Contratos de concessão. Recuperado de http://www.cpc.org.br/pdf/ICPC01_R1.pdf

Comitê de Pronunciamentos Contábeis (2010). Orientação OCPC 05 - Contratos de concessão. Recuperado de http://www.cpc.org.br/

Comitê de Pronunciamentos Contábeis (2014). Orientação OCPC 08 - Reconhecimento de determinantes ativos e passivos nos relatórios contábil-financeiros de propósito geral das distribuidoras de energia elétrica. Recuperado de http://www.cpc.org.br/

Comissão de Valores Mobiliários (2014). Deliberação Normativa no 727. Novembro de 2014. Recuperado de http://www.cvm.gov.br/ /legislacao/

Gomes, M. E. R. (2013). Estudo do impacto da adoção da ICPC 01 nas decisões gerenciais considerando as normas societárias e regulatórias nas empresas de transmissão de energia elétrica do Brasil. Dissertação (Mestrado), Universidade Presbiteriana Mackenzie, São Paulo.

Ho, S. M., \& Wong, K S. (2001). A study of corporate disclosure practice and effectiveness in Hong Kong. Journal of International Financial Management and Accounting, 12(1), 75102.

Hodge, F. D. (2003). "Investors' perceptions of earnings quality, auditor independence, and the usefulness of audited financial information." Accounting Horizons, 37-48.

Hoppe, A. A. (2012). Estudo sobre as diferenças de práticas contábeis nas demonstrações contábeis societárias e regulatórias de distribuidoras de energia elétrica no Brasil. Dissertação (Mestrado em Ciências Contábeis e Atuariais), Pontifícia Universidade Católica de São Paulo, São Paulo.

Morton, J. R. (1974). Qualitative Objectives of Financial Accounting: A Comment on Relevance and Understandability. Journal Of Accounting Research, 12(2), 288-298.

Ohara, E. H. (2014). Finanças do setor elétrico: demonstrações societárias vs regulatórias. Monografia (Especialização) - Curso de Perícia Contábil, AVM Faculdade Integrada, Brasília.

Ribeiro, M. G. C., Macedo, M. A. S., \& Marques, J. A. V. C. (2012). Análise da relevância de indicadores financeiros e não financeiros na avaliação de desempenho organizacional: um estudo exploratório no setor brasileiro de distribuição de energia elétrica. Revista de Contabilidade e Organizações, 6(15), 61-79.

Ribeiro, R. (2016). O que pensam os contadores e reguladores sobre as diferenças da contabilidade societária e da contabilidade regulatória do setor elétrico no Brasil após a emissão da OCPC 08. Dissertação (Mestrado) - Curso de PPGCC, Universidade Federal do Rio de Janeiro, Rio de Janeiro. 
Zimmerman, J. L. (2013). Myth: external financial reporting quality has a first-order effect on firm value. Accounting Horizons, American Accounting Association, 27(4), 887-894.

Zoysa, A. de, \& Rudkin, K. (2010). An investigation of perceptions of company annual report users in Sri Lanka. Int Journal of Emerging Mkts, 5(2), 183-202. 